\title{
Book Review: Exemplary Practices in Marine Science Education
}

\author{
Kanesa Duncan Seraphin ${ }^{1 *}$, Jennifer L. East ${ }^{2}$ and Lyndell N. Whitley ${ }^{3}$ \\ 1 University of Hawai'i Sea Grant College Program, School of Ocean and Earth Science and Technology, Honolulu, HI, \\ United States, ${ }^{2}$ Oregon State University Sea Grant College Program, Corvallis, OR, United States, ${ }^{3}$ Department of Biological \\ Sciences, Wrigley Institute for Environmental Studies, University of Southern California, Los Angeles, CA, United States
}

Keywords: ocean literacy, identity, education, environment, marine science

\section{A Book Review on \\ Exemplary Practices in Marine Science Education}

Geraldine Fauville, Diana L. Payne, Meghan E. Marrero, Annika Lantz-Anderson, and Fiona Crouch (Cham, Switzerland: Springer), 2018, 452 pages, ISBN: 9783319907772.

Humans and the ocean are inextricably interconnected. The ocean drives the water cycle, governs climate, and provides a diverse number of ecosystem services (Barbier et al., 2012). Modern societies are not only physically connected by the ocean, but they also depend on and are shaped by it. Moreover, just as the ocean has influenced humankind, so too have we impacted the ocean and the systems within it-initiating the Anthropocene Epoch (Steffen et al., 2011).

There is a need for the global public to develop a better (1) understanding of how the ocean functions, (2) ability to communicate about the ocean, and (3) capacity to make informed decisions about its resources. Education is one of the most important tools available to support the growth of ocean literacy on a global level. As we embark on missions to improve public understanding of the ocean, it is critical to reflect on and learn from prior research and programs.

In 2018, Fauville et al. published the first international book on marine science education and ocean literacy. Our review examines the contents of this edited volume, which contains 24 contributed chapters. Fauville et al. (2018) begin with the history of ocean literacy, which is defined as a person's understanding of the ocean's influence on them and their influence on the ocean (Schoedinger et al., 2010). The introduction details many of the challenges inherent in communicating ocean and marine science. For example, the public not only lacks familiarity with the environment, but marine ecology is also inherently complex. Moreover, the tangle of social, financial, and political issues associated with marine resources makes communication and productive discourse difficult. In addition, misinformation is easily spread in this modern, digital age-impeding people's ability to assess the accuracy of information (Thaler and Shiffman, 2015).

The collected chapters synthesize research from the marine science education field, providing both a historical perspective and a road map for future research. Readers are encouraged to use the authors' examples as models for their own communities, needs, and interests. Throughout the chapters, there is an emphasis on the need to share data across the global marine science education community. Readers are encouraged to join the international network of scholars, educators, and citizens working to advance participation in marine science education and conservation. The majority of the book is split into two sections: research and practice. The collected works describe research and interventions across age levels, social demographics, educational settings, and literacy levels.

Research and evaluation studies shared in the book reflect different methods to achieve marine science education outcomes in both formal and informal educational settings. For example, Niedoszytko et al. (2018) report on a 12-year program exploring the integration of a combined formal-informal program related to the Baltic Sea. The longitudinal project targeted youth 6 
times during their education journey, from ages 6 to 17 years, and included evaluation of student experiences, marine education, and ocean literacy. Walters and Bishop (2018) use research by Almarode et al. (2014) to support the causal connection between students' feelings of intellectual capacity in Science, Technology, Engineering, and Mathematics (STEM) and future career choices. Riedinger and Taylor (2018) discuss the body of research on field trips' influence on student interest and attitudes (Behrendt and Franklin, 2014) and provide suggestions for effective field trips, highlighting practical concerns such as the preparation of chaperones. Robinson and Murray (2018) speak to the importance of evaluating programs and discuss science communication theory, providing examples from the National Marine Aquarium in the United Kingdom.

For practitioners, there are examples of programs developed, implemented, and evaluated in various educational settings and several countries. Readers will likely appreciate the descriptions of how programs were designed and implemented as well as strategies for assessing success and evaluating programs. Respected authors share their experience over many years as marine science education researchers, practitioners, or both. The scope of programs presented spans a wide range and includes connecting graduate students with K-12 classrooms, leveraging parent chaperones, conducting professional development, assessing longitudinal studies of aquarium visitors, engaging citizen scientists, providing meaningful field experiences, and teaching in multicultural settings-all in the context of ocean literacy. Across programs, there is a shared goal to create positive connections as well as a sense of responsibility and stewardship for the ocean environment. Authors urge the cultivation of empathy toward marine life and how it is researched.

Another recurring theme across the practitioner section is the integration of modern cultural influences on ocean literacy. The collected works repeatedly advocate for creatively pushing

\section{REFERENCES}

Almarode, J. T., Subotinik, R. F., Crowe, E., Tai, R. H., Lee, G. M., and Nowlin, F. (2014). Specialized high schools and talent search programs: Incubators for adolescents with high ability in STEM disciplines. J. Adv. Acad. 25, 307-331. doi: $10.1177 / 1932202 X 14536566$

Baker, G. J., and Readman, E. (2018). "Closer to blue," in Exemplary Practices in Marine Science Education, eds G. Fauville, D. L. Payne, M. E. Marrero, A. Lantz-Anderson, and F. Crouch (Cham: Springer), 377-400.

Barbier, E. B., Hacker, S. D., Koch, E. W., Stier, A., and Silliman, B. (2012). "Estuarine and coastal ecosystems and their services," in Volume 12: Ecological Economics of Estuaries and Coasts. Treatise on Estuarine and Coastal Science, eds M. van den Belt, and R. Costanza, Series eds, E. Wolanski, and D. McLusky (Waltham, MA: Academic Press), 109-127.

Behrendt, M., and Franklin, T. (2014). A review of research on school field trips and their value in education. Int. J. Environ. Sci. Educ. 9, 235-245. doi: 10.12973/ijese.2014.213a

Brill, C. H., Lawrence, L., Nuss, S. M., Cackowski, C., and Sharpe, K. (2018). “Out of the tower and into the classroom: marine science graduate students as K-12 classroom contributors," in Exemplary Practices in Marine Science Education, eds G. Fauville, D. L. Payne, M. E. Marrero, A. Lantz-Anderson, and F. Crouch (Cham: Springer), 241-256.

Fauville, G. Payne, D. L., Marrero, M. E., Lantz-Anderson, A., and F. Crouch. (2018). Exemplary Practices in Marine Science Education. Cham: Springer. doi: 10.1007/978-3-319-90778-9 the boundaries of traditional science education. Jaksha (2018), for example, presents the idea of ocean identity, a concept derived from environmental identity (Payne, 2000), as an index to quantify the combination of emotion, feelings, and connections that predict a person's actions and behaviors. Other authors also emphasize the need to move beyond campaigns that stimulate interest and knowledge-toward programs that involve more participatory conservation and problem-solving strategies. The use of appropriate role models is another uniting theme across chapters. Authors, like Brill et al. (2018), advocate getting experts out of the ivory tower and into the classroom. Similarly, the importance of providing students and the public with authentic research experiences is covered in multiple chapters, from biofilm and biodiversity projects targeting primary school students and teachers in Sweden, the United States, and Norway (Frederick et al., 2018), to oceanaccess projects for socially disadvantaged participants of all ages in the United Kingdom (Baker and Readman, 2018), to general information on meaningful watershed educational experiences in the United States (Nuss et al., 2018).

The collected chapters are optimistic, and yet they are also written with a sense of urgency. The writing itself is easily accessible and provides a useful history and context to ocean literacy. The authors cover issues in formal, informal, and community settings across several countries and cultures. It is recommended as a resource for educators and researchers of marine science as well as other science education disciplines.

\section{AUTHOR CONTRIBUTIONS}

KS coordinated the book review writing, editing, and submission. JE and LW both provided substantial contributions to the writing and revision of the article.

Frederick, J. A., Gotensparre, S., Jacobs, D., Källström, B., and Olsson, M. (2018) "The virtue project and the biofilms and biodiversity project: an international collaboration in marine science education," in Exemplary Practices in Marine Science Education, eds G. Fauville, D. L. Payne, M. E. Marrero, A. LantzAnderson, and F. Crouch (Cham: Springer), 257-288.

Jaksha, A. (2018). "Leveraging ocean identity in education to impact students" conservation practices," in Exemplary Practices in Marine Science Education, eds G. Fauville, D. L. Payne, M. E. Marrero, A. Lantz-Anderson, and F. Crouch (Cham: Springer), 93-107.

Niedoszytko, G., Wojcieszek, D., Podlesinska, W., and Borowiak, K. (2018). "Implementing ocean literacy through the bond of informal and formal education," in Exemplary Practices in Marine Science Education, eds G. Fauville, D. L. Payne, M. E. Marrero, A. Lantz-Anderson, and F. Crouch (Cham: Springer), 123-142. doi: 10.1007/978-3-319-90778-9_8

Nuss, S. M., Sharpe, K., Brill, C. H. Lawrence, L., and Cackowski, C. (2018). "Building capacity for meaningful watershed educational experiences," in Exemplary Practices in Marine Science Education, eds G. Fauville, D. L. Payne, M. E. Marrero, A. Lantz-Anderson, and F. Crouch (Cham: Springer), 323-340.

Payne, P. (2000). Identity and environmental education. Environ. Educ. Res. 7, 67-88. doi: 10.1080/13504620124658

Riedinger, K., and Taylor, A. (2018). "Leveraging parent chaperones to support youths' learning during an out-of-school field trip to a marine science field station," in Exemplary Practices in Marine Science Education, eds G. Fauville, D. L. Payne, M. E. Marrero, A. Lantz-Anderson, and F. Crouch (Cham: Springer), 59-80. 
Robinson, A., and Murray, N. (2018). "Evaluating ocean learning-the principles and practicalities of evaluating formal education audiences in an informal education environment," in Exemplary Practices in Marine Science Education, eds G. Fauville, D. L. Payne, M. E. Marrero, A. Lantz-Anderson, and F. Crouch (Cham: Springer), 143-156.

Schoedinger, S., Tran, L. U., and Whitley, L. (2010). From the principles to the scope and sequence: a brief history of the ocean literacy campaign. J. Mar. Educ. 3, 3-7.

Steffen, W. Grinevald, J., Crutzen, P., and McNeill, J. (2011). The anthropocene: conceptual and historical perspectives. Philos. Trans. Ser. 369, 842-867. doi: 10.1098/rsta.2010.0327

Thaler, A. D., and Shiffman, D. (2015). Fish tales: combating fake science in popular media. Ocean Coast. Manage. 115, 88-91. doi: 10.1016/ j.ocecoaman.2015.04.005

Walters, H., and Bishop, K. (2018). "Systematic and longitudinal research to support and improve the national ocean sciences bowl: findings from seventeen years of study," in Exemplary Practices in Marine Science Education, eds G. Fauville, D. L. Payne, M. E. Marrero, A. Lantz-Anderson, and F. Crouch (Cham: Springer), 81-92.

Conflict of Interest Statement: The authors declare that the research was conducted in the absence of any commercial or financial relationships that could be construed as a potential conflict of interest.

Copyright (c) 2019 Seraphin, East and Whitley. This is an open-access article distributed under the terms of the Creative Commons Attribution License (CC BY). The use, distribution or reproduction in other forums is permitted, provided the original author(s) and the copyright owner(s) are credited and that the original publication in this journal is cited, in accordance with accepted academic practice. No use, distribution or reproduction is permitted which does not comply with these terms. 